\title{
Prenatal essential fatty acid deficiency in mice results in long-term gender-specific effects on body weight and glucose metabolism
}

\author{
VILBORG PALSDOTTIR ${ }^{1,2}$, ANNA WICKMAN ${ }^{3}$, BIRGITTA STRANDVIK $^{1,4}$, \\ BRITT G. GABRIELSSON ${ }^{5}$ and BOB OLSSON ${ }^{2}$
}

\begin{abstract}
Departments of ${ }^{1}$ Paediatrics, ${ }^{2}$ Molecular and Clinical Medicine, and ${ }^{3}$ Physiology, The Sahlgrenska Academy, University of Gothenburg, 41345 Gothenburg; ${ }^{4}$ Department of Biosciences and Nutrition, NOVUM, Karolinska Institutet, 14157 Huddinge; ${ }^{5}$ Department of Chemical and Biological Engineering, Chalmers University of Technology, 41296 Gothenburg, Sweden
\end{abstract}

Received March 4, 2011; Accepted May 11, 2011

DOI: 10.3892/mmr.2011.490

\begin{abstract}
Essential fatty acids are important for normal growth and development in early life. However, the long-term effects of prenatal essential fatty acid deficiency (EFAD) on the adult metabolism remain to be determined. The aim of this study was to investigate the effects of an EFAD diet given to mice during late gestation on body weight and body composition, and metabolism in the adult offspring. Pregnant dams were given an EFAD or a control diet during the last 10 days of gestation. After delivery, all mice were fed normal chow and the body weight of the offspring was measured weekly. Furthermore, food intake, energy expenditure and intraperitoneal glucose tolerance were analysed in the adult offspring in addition to body composition (analysed by dual-energy $\mathrm{X}$-ray absorptiometry), plasma levels of leptin, triglycerides and cholesterol. The body weight was lower in the EFAD offspring as compared to the controls during the first 4 weeks of age, and remained lower in the females throughout the study. Lean body mass and plasma leptin levels were also lower in the female EFAD offspring as compared to the controls. Male EFAD offspring were found to have higher fasting glucose and insulin levels as well as higher insulin levels during the glucose tolerance test compared to the controls. However, no differences were found in blood lipids, food intake or energy expenditure between EFAD and control mice of either gender. These results demonstrate that an EFAD diet given during the last 10 days of gestation results in long-term gender-specific effects on body weight and insulin sensitivity in the adult offspring.
\end{abstract}

Correspondence to: Dr Vilborg Palsdottir, Department of Molecular and Clinical Medicine, University of Gothenburg, Vita Stråket 15, 41345 Gothenburg, Sweden

E-mail: vilborg.palsdottir@medic.gu.se

Key words: maternal diet, essential fatty acid deficiency, body composition, glucose metabolism, energy expenditure

\section{Introduction}

Maternal nutritional status during pregnancy and lactation is a significant factor in the adult health of the offspring. The combination of inadequate nutrition early in life and overnutrition later in life is thought to increase the risk of obesity and associated metabolic disorders such as type 2 diabetes (1). Essential fatty acids are required for normal growth and development in early life, and deficiency in humans results in growth retardation during the neonatal period (2). Low plasma levels of essential fatty acids have been observed in children with malnutrition (3-5), and in preterm infants (6). However, essential fatty acid deficiency (EFAD) in humans rarely occurs in isolation, but is common in general undernutrition or in dietary protein deficiency. Therefore, experimental animal models are useful to separate the specific long-term effects of EFAD from those of undernutrition and protein malnutrition.

Adult rats subjected to EFAD from perinatal life and onwards had decreased body weight, but increased insulin levels before and during a glucose tolerance test to which these rats were subjected (7). In diabetes-prone BB rats, an EFAD diet commencing at 10 weeks of age reduced the incidence of autoimmune diabetes, and this reduction was associated with the depletion of omega- 6 fatty acids (8). Metabolites of omega- 6 fatty acids, such as prostaglandin $\mathrm{E}_{2}$, are known to suppress glucose-induced insulin secretion (9) and the lower levels of these metabolites in EFAD may be responsible for the increase in insulin response. Although results of these studies showed that EFAD has an impact on insulin levels in adults, little is known about the long-term effects of EFAD exposure during fetal life.

In rats, perinatal deficiency of essential omega-3 fatty acids increased blood pressure (10) and food intake (11) during adult life. Male offspring of rats fed an EFAD diet during the latter half of the gestation and throughout lactation initially had a slow growth rate and low leptin levels $(12,13)$. However, at adult age the leptin levels of the male rats normalized and they weighed more than the controls (14). The prenatal contribution to the long-term metabolic effects of EFAD, however, remains to be elucidated. 
Our hypothesis was that exposure to EFAD alone during the latter half of gestation in mice would affect anthropometry as well as glucose metabolism during adult life. To test this, an EFAD diet was given to mouse dams during the latter half of gestation and the body weight, body composition, energy expenditure, food intake, glucose tolerance, plasma insulin, leptin and lipids were studied in the adult offspring.

\section{Materials and methods}

Animals and diets. The mice were housed in accordance with international laboratory guidelines and all experiments were reviewed and approved by the local Ethics Committee for Animal Studies at the Administrative Court of Appeals in Gothenburg, Sweden. Time-mated C57BL/6 mice from Taconic (Ejby, Denmark) were obtained at 9 days of gestation and housed in individual cages until the end of lactation. The animals were kept in constant conditions at $22^{\circ} \mathrm{C}$ and constant humidity with a 12-h light/dark cycle, and were given ad libitum access to food and tap water. On day 11 of gestation the dams were randomly divided into two groups ( $\mathrm{n}=8$ in each group), and given either an EFAD or an isoenergetic control diet (Lactamin AB, Kimstad, Sweden; formed to pellets by Morinaga Milk Industry Co., Ltd.; Tokyo, Japan). The two diets constituted 7\% fat and differed only in lipid composition in that the EFAD diet contained only hydrogenated rapeseed oil without trans fatty acids and the control diet contained mainly soybean oil (Table I). The fatty acid composition of the diets was analyzed by gas-liquid chromatography as previously described (12).

The body weight of the dams was recorded on days 11 and 18 of gestation and the food intake between day 11 of gestation and delivery was measured by recording the weight of the pellets in each cage every third day and after delivery. All of the dams received a standard diet (Global 2016, Harlan Teklad, Madison, WI, USA) (Table I) after delivery, and the litter size was adjusted to 6 pups per litter. Randomly chosen newborn pups from 3 different litters in each group were sacrificed and the livers were collected and frozen at $-70^{\circ} \mathrm{C}$ for subsequent analysis of fatty acid composition. At 4 weeks of age, the pups were separated according to gender, housed 3-5 mice per cage and fed the standard diet.

Fatty acids analysis. Livers from newborn pups were homogenized in water and isopropanol at a ratio of 1:7. The mixture was sonicated and the lipids were extracted according to the method of Rose and Oklander (15). Lipid classes were separated by high-performance liquid chromatography as previously described (16), and the fatty acids in the total phospholipid fraction were methylated. The fatty acid methyl esters were analyzed by capillary gas-liquid chromatography (Hewlett Packard 6890, Hewlett Packard, Wilmington, DE, USA) as previously described (12). The separation was recorded with HP GC ChemStation software. Heneicosanoic acid (21:0) was used as the internal standard, and the fatty acid methyl esters were identified by comparison with retention times of pure reference substances (Nu-Chek Prep, Inc., Elysian, MN, USA).

Body weight, food intake and body composition. Body weight was measured weekly at 1-15 weeks of age. Food intake of the
Table I. Composition of the experimental diets and the standard diet and fatty acid composition of the dietary fat.

\begin{tabular}{lccc}
\hline Ingredients (g/kg diet) & $\begin{array}{c}\text { Control } \\
\text { diet }\end{array}$ & $\begin{array}{c}\text { EFAD } \\
\text { diet }\end{array}$ & $\begin{array}{c}\text { Standard } \\
\text { diet }\end{array}$ \\
\hline Protein & 200.0 & 200.0 & 184.7 \\
Crude protein & - & - & 184.7 \\
Casein & 200.0 & 200.0 & - \\
Carbohydrate & 640.0 & 640.0 & 619.2 \\
Corn starch & - & - & 575.0 \\
Potato starch & 540.0 & 540.0 & - \\
Sucrose & - & - & 44.2 \\
Glucose & 100.0 & 100.0 & - \\
Fat & 70.0 & 70.0 & 46.4 \\
Soybean oil & 57.0 & 0.0 & 46.4 \\
Hydrogenated rapeseed oil & 13.0 & 70.0 & - \\
Fibre & 40.0 & 40.0 & 43.1 \\
Crude fibre & - & - & 43.1 \\
Cellulose & 40.0 & 40.0 & - \\
Ash & - & - & 61.9 \\
Mineral mix & $40.0^{\mathrm{a}}$ & $40.0^{\mathrm{a}}$ & $33.6^{\mathrm{b}}$ \\
Vitamin mix & $10.0^{\mathrm{c}}$ & $10.0^{\mathrm{c}}$ & $11.1^{\mathrm{d}}$ \\
\hline
\end{tabular}

Fatty acids (mol \% of total)

\begin{tabular}{lrrr}
\hline $12: 0$ & $<0.01$ & 0.1 & $<0.01$ \\
$14: 0$ & 0.1 & 0.1 & 0.1 \\
$16: 0$ & 14.8 & 5.9 & 11.8 \\
$16: 1 \mathrm{n}-7$ & 0.1 & $<0.01$ & 0.1 \\
$18: 0$ & 2.0 & 45.6 & 3.5 \\
$18: 1 \mathrm{n}-9$ & 19.0 & 0.3 & 21.3 \\
$18: 2 \mathrm{n}-6$ & 58.4 & 0.1 & 56.9 \\
$18: 3 \mathrm{n}-3$ & 4.7 & $<0.01$ & 5.4 \\
$20: 0$ & 0.3 & 8.5 & 0.3 \\
$22: 0$ & 0.2 & 38.7 & 0.4 \\
$24: 0$ & 0.2 & 0.8 & 0.2 \\
\hline
\end{tabular}

EFAD, essential fatty acid deficient. ${ }^{\mathrm{a} C o n t a i n s}$ the following ingredients $\left(\mathrm{g} / \mathrm{kg}\right.$ diet): $\mathrm{KH}_{2} \mathrm{PO}_{4}, 13.6 ; \mathrm{CaCO}_{3}, 14.36 ; \mathrm{KCl}, 1.0$; $\mathrm{NaCl}, 7.2 ; \mathrm{MgSO}_{4} \cdot \mathrm{H}_{2} \mathrm{O}, 2.0 ; \mathrm{FeC}_{6} \mathrm{H}_{5} \mathrm{O}_{7} \cdot 5 \mathrm{H}_{2} \mathrm{O}, 1.3 ; \mathrm{MnO}, 0.11$; $\mathrm{Cu}_{2} \mathrm{C}_{6} \mathrm{H}_{4} \mathrm{O}_{7} \cdot 2.5 \mathrm{H}_{2} \mathrm{O}, 0.024 ; \mathrm{Zn}_{3}\left(\mathrm{C}_{6} \mathrm{H}_{5} \mathrm{O}_{7}\right) 2 \cdot 2 \mathrm{H}_{2} \mathrm{O}, 0.016 ; \mathrm{CoCl}_{2} \cdot 6 \mathrm{H}_{2} \mathrm{O}$, $0.0008 ; \mathrm{KAl}\left(\mathrm{SO}_{4}\right) 2 \cdot 2 \mathrm{H}_{2} \mathrm{O}, 0.0032 ; \mathrm{NaF}, 0.01 ; \mathrm{KIO}_{3}, 0.0036$; $\mathrm{Na}_{2} \mathrm{~B}_{4} \mathrm{O}_{7} \cdot 10 \mathrm{H}_{2} \mathrm{O}, 0.0008 ; \mathrm{Na}_{2} \mathrm{SeO}_{3} \cdot 5 \mathrm{H}_{2} \mathrm{O}, 0.0004$; and $\mathrm{Na}_{2} \mathrm{MoO}_{4} \cdot 2 \mathrm{H}_{2} \mathrm{O}$, 0.0004. ${ }^{\mathrm{b} C o n t a i n s}$ the following ingredients $(\mathrm{g} / \mathrm{kg}$ diet): $\mathrm{Ca}, 10.8 ; \mathrm{P}$, 7.2; Na, 2.8; K, 5.9; Cl, 4.6; Mg, 2.3; Zn, 0.08; Mn, 0.124; Cu, 0.015; I, 0.012; Fe, 0.24; Se, 0.0002; Co, 0.0006; and Cr, 0.0005. ' Contains the following ingredients $(\mathrm{mg} / \mathrm{kg}$ diet): retinol, 3.57; cholecalciferol, 0.0375; $\alpha$-tocopherol, 42; menadione, 7.75; folic acid, 0.5; nicotinic acid, 40; thiamin, 4; riboflavin, 12; pyridoxine, 5; cyanocobalamin, 0.02 ; ascorbic acid, 500; calcium pantothenate $(45 \%)$, 11; biotin (2\%), 3; choline chloride 50\%, 1000; and myo-inositol, $30 .{ }^{\mathrm{d}}$ Contains the following ingredients $(\mathrm{mg} / \mathrm{kg}$ diet): retinol, 4.8 ; cholecalciferol, 0.038; $\alpha$-tocopherol, 100.0; menadione, 51.3; folic acid, 3.4; nicotinic acid, 64.5; thiamin, 17.2; riboflavin, 14.5; pyridoxine, 18.5; cyanocobalamin, 0.080; pantothenic acid, 32.2; biotin, 0.4; choline, 1095.0; B-carotene, 3.1; and myo-inositol, 1630.0. 
offspring (3-5 mice/cage) was recorded at week 6 by weighing the pellets in each cage three times per week and calculating the average food intake as $\mathrm{kJ}$ per $\mathrm{g}$ body weight per day. Body composition was measured by dual-energy X-ray absorptiometry (PIXImus Imager, GE Lunar Corp., Madison, WI, USA) under isoflurane anesthesia (Baxter Medical AB, Kista, Sweden) at 15 weeks of age as previously described (17). Heads from the animals were excluded from all analyses, since the entire mouse did not fit into the PIXImus scan area.

Energy expenditure and respiratory exchange ratio. At 10 weeks of age, $\mathrm{O}_{2}$ consumption $\left(\mathrm{VO}_{2}\right)$ and $\mathrm{CO}_{2}$ production $\left(\mathrm{VCO}_{2}\right)$ were measured during a 2 -h period at thermoneutrality $\left(30^{\circ} \mathrm{C}\right)$ using an indirect calorimetric system (Columbus Instruments, Columbus, OH, USA) as previously described (18). The respiratory exchange ratio (RER) was calculated as the ratio between $\mathrm{CO}_{2}$ production and $\mathrm{O}_{2}$ consumption; $\mathrm{RER}=$ $\mathrm{VCO}_{2} / \mathrm{VO}_{2}$. Energy expenditure (EE) was calculated from the RER and $\mathrm{VO}_{2}$ by using the formula $\mathrm{EE}=(3.815+1.232 \mathrm{x}$ RER $)$ $\mathrm{x} \mathrm{VO}_{2} \mathrm{x} 4.1868$, according to the manufacturer's instructions.

Glucose tolerance test. The intraperitoneal glucose tolerance test was performed in unanesthetized 12-week-old mice that were fasted overnight (14-16 h). Samples of blood glucose $(3 \mu \mathrm{l})$ were analyzed with an Accu-Chek Compact glucometer (F. Hoffmann-La Roche Ltd., Basel, Switzerland) prior to injection of D-glucose $(2 \mathrm{~g} / \mathrm{kg}$ body weight), and at 15, 30, 60 and 120 min after injection. Blood samples for insulin analysis $(20 \mu \mathrm{l})$ were collected in heparinized tubes from the tip of the tail prior to injection and at 2, 5, 15 and 60 min after injection. The plasma was frozen at $-80^{\circ} \mathrm{C}$ until analysis.

Plasma analysis. Plasma insulin levels during the glucose tolerance test were analyzed using an enzyme-linked immunosorbent assay (ELISA, Crystal Chem. Inc., Downers Grove, IL, USA). Additional blood samples $(60 \mu \mathrm{l})$ were collected in heparinized tubes from the tip of the tail at 15 weeks of age in unanesthetized mice, fasted for $6 \mathrm{~h}$, and the plasma was stored at $-80^{\circ} \mathrm{C}$ until analysis. Plasma leptin concentrations were analyzed by ELISA (Crystal Chem. Inc.), and triglycerides and cholesterol by Infinity ${ }^{\mathrm{TM}}$ reagents (Thermo Fisher Scientific, Waltham, MA, USA).

Statistical analysis. Data are presented as the mean \pm SEM. Equal distributions were tested by the Kolmogorov-Smirnov test. Comparisons between EFAD and control offspring of the same gender were tested using the Student's t-test or Mann-Whitney $U$ test for data with unequal distributions. Differences in body weight and differences in glucose and insulin levels during the glucose tolerance test were tested by one-way repeated measures ANOVA. The Chi-square test was used to determine differences in the time of delivery. All of the tests were performed using SPSS 16.0 (SPSS, Chicago, IL, USA). $\mathrm{P}<0.05$ was considered to be statistically significant.

\section{Results}

Gestation and delivery. There was no difference in the body weight of the dams on day 11 of gestation, when they were
Table II. Fatty acid composition of hepatic total phospholipids from newborn pups.

\begin{tabular}{lcc}
\hline Fatty acid (mol \%) & Control & EFAD \\
\hline $14: 0$ & $0.320 \pm 0.050$ & $0.410 \pm 0.020$ \\
$16: 0$ & $28.980 \pm 0.360$ & $26.740 \pm 0.420^{\mathrm{a}}$ \\
$16: 1 \mathrm{n}-7$ & $1.140 \pm 0.060$ & $3.480 \pm 0.160^{\mathrm{a}}$ \\
$18: 0$ & $16.440 \pm 0.240$ & $16.350 \pm 0.100$ \\
$18: 1 \mathrm{n}-9$ & $9.580 \pm 0.370$ & $20.550 \pm 1.450^{\mathrm{a}}$ \\
$18: 2 \mathrm{n}-6$ & $11.460 \pm 0.570$ & $4.930 \pm 0.350^{\mathrm{a}}$ \\
$18: 3$ n-6 & $0.320 \pm 0.010$ & $0.430 \pm 0.040^{\mathrm{a}}$ \\
$20: 0$ & $0.050 \pm 0.002$ & $0.060 \pm 0.004$ \\
$20: 2 \mathrm{n}-6$ & $0.310 \pm 0.010$ & $0.070 \pm 0.005^{\mathrm{a}}$ \\
$20: 3$ n-9 & $0.140 \pm 0.030$ & $4.300 \pm 0.090^{\mathrm{a}}$ \\
$20: 3 \mathrm{n}-6$ & $0.500 \pm 0.010$ & $0.480 \pm 0.050$ \\
$22: 0$ & $0.250 \pm 0.020$ & $0.250 \pm 0.010$ \\
$20: 4$ n-6 & $17.280 \pm 0.420$ & $13.560 \pm 0.640^{\mathrm{a}}$ \\
$20: 5 \mathrm{n}-3$ & $0.080 \pm 0.0050$ & $0.100 \pm 0.010$ \\
$24: 0$ & $0.270 \pm 0.010$ & $0.260 \pm 0.020$ \\
$24: 1 \mathrm{n}-9$ & $0.490 \pm 0.030$ & $0.610 \pm 0.040$ \\
$22: 6 \mathrm{n}-3$ & $12.410 \pm 0.680$ & $7.410 \pm 0.520^{\mathrm{a}}$ \\
$\mathrm{n}-6: \mathrm{n}-3$ ratio & $2.410 \pm 0.140$ & $2.610 \pm 0.130$ \\
$\Sigma$ SFA & $46.300 \pm 0.360$ & $44.070 \pm 0.350^{\mathrm{a}}$ \\
$\sum$ MUFA & $11.210 \pm 0.400$ & $24.650 \pm 1.320^{\mathrm{a}}$ \\
$\sum$ PUFA & $42.490 \pm 0.650$ & $31.280 \pm 0.990^{\mathrm{a}}$ \\
& & \\
\hline
\end{tabular}

EFAD, essential fatty acid deficient. Data are expressed as the mean $\pm \operatorname{SEM}(n=3) .{ }^{\mathrm{a}} \mathrm{p}<0.05$ (Mann-Whitney U test).

divided to receive either an EFAD or a control diet. The dams given the EFAD diet gained less weight and on day 18 of gestation they weighed $32.5 \pm 1.1 \mathrm{~g}$ as compared to the control dams, with a weight of $36.4 \pm 0.4 \mathrm{~g}(\mathrm{p}<0.05)$. However, the cumulative food intake during the 10 days of experimental diets did not differ between the groups $(69.4 \pm 4.1$ vs. $65.6 \pm 2.7 \mathrm{~g}$, EFAD vs. control, respectively). No differences were found in length of gestation ( $20.3 \pm 0.2$ vs. $20.2 \pm 0.2$ days, EFAD vs. control), litter size (5.8 \pm 0.8 vs. $6.8 \pm 0.2$ pups, EFAD vs. control litters) or litter gender distribution (data not shown) between the EFAD and control groups.

Fatty acid composition in newborn pups. The fatty acid composition of total phospholipids in livers from newborn EFAD pups differed from that of control pups (Table II). The proportion of monounsaturated fatty acid (MUFA), palmitoleic acid (16:1 n-7) and oleic acid (18:1 n-9) was higher in the EFAD livers compared to the controls. Conversely, the proportion of a number of polyunsaturated fatty acids (PUFA), such as linoleic acid (18:2, n-6), arachidonic acid (20:4, n-6) and docosahexaenoic acid (22:6, n-3) was lower in the EFAD livers. Additionally, the proportion of mead acid (20:3, n-9) was markedly higher in livers from EFAD pups than in the control livers (Table II).

Body weight, food intake and energy expenditure. The body weight of EFAD pups was lower than that of controls during 
Table III. Anthropometric and metabolic characteristics of the adult offspring.

\begin{tabular}{|c|c|c|c|c|}
\hline & Male control & Male EFAD & Female control & Female EFAD \\
\hline \multicolumn{5}{|l|}{ Ten-week-old mice } \\
\hline Energy expenditure $(\mathrm{kJ} / \mathrm{kg} / \mathrm{min})$ & $740 \pm 42$ & $756 \pm 42$ & $812 \pm 32$ & $826 \pm 17$ \\
\hline Respiratory exchange ratio & $0.84 \pm 0.02$ & $0.82 \pm 0.02$ & $0.84 \pm 0.02$ & $0.81 \pm 0.03$ \\
\hline \multicolumn{5}{|l|}{ Fifteen-week-old mice } \\
\hline Body weight (g) & $35.60 \pm 0.80$ & $35.30 \pm 0.80$ & $27.60 \pm 0.90$ & $25.00 \pm 0.80^{\mathrm{a}}$ \\
\hline Lean body mass (g) & $25.50 \pm 0.50$ & $25.30 \pm 0.40$ & $18.60 \pm 0.40$ & $17.20 \pm 0.40^{\mathrm{a}}$ \\
\hline Lean body mass (\%) & $80.60 \pm 0.70$ & $80.90 \pm 1.50$ & $73.90 \pm 1.90$ & $77.30 \pm 1.80$ \\
\hline Fat mass $(\mathrm{g})$ & $6.20 \pm 0.30$ & $6.20 \pm 0.60$ & $6.80 \pm 0.70$ & $5.20 \pm 0.50$ \\
\hline Fat mass $(\%)$ & $19.40 \pm 0.70$ & $19.10 \pm 1.50$ & $26.00 \pm 1.90$ & $22.80 \pm 1.80$ \\
\hline Leptin (ng/ml) & $11.00 \pm 1.80$ & $12.40 \pm 2.90$ & $13.30 \pm 1.70$ & $7.10 \pm 1.80^{\mathrm{a}}$ \\
\hline Triglycerides (mmol/l) & $0.93 \pm 0.07$ & $0.86 \pm 0.05$ & $0.79 \pm 0.08$ & $0.77 \pm 0.06$ \\
\hline Cholesterol (mmol/l) & $3.03 \pm 0.22$ & $3.10 \pm 0.20$ & $2.46 \pm 0.22$ & $1.83 \pm 0.24$ \\
\hline
\end{tabular}

EFAD, essential fatty acid deficient. Data are expressed as mean \pm SEM $(n \geq 6) .{ }^{a} p<0.05$ (Student's t-test), calculated separately for each gender.

the first 4 weeks $(\mathrm{p}<0.001)$. The body weight continued to be lower in the female EFAD pups $(\mathrm{p}<0.01)$, but not in the males, throughout the experiment (Fig. 1). The food intake did not differ between the control and EFAD males $(1.96 \pm 0.003$ vs. $1.93 \pm 0.001 \mathrm{~kJ} / \mathrm{g}$ mouse/day) or females $(2.15 \pm 0.002 \mathrm{vs}$. $2.10 \pm 0.002 \mathrm{~kJ} / \mathrm{g}$ mouse/day) at 6 weeks of age. Furthermore, no differences were observed in EE in relation to body weight or in RER between the groups (Table III).

Body composition, plasma leptin and plasma lipids. Body weight and lean body mass were lower in EFAD females, but not in EFAD males, compared to the controls at 15 weeks of age (Table III). There was also a trend $(p=0.08)$ towards lower fat mass in EFAD females compared to the controls, and plasma leptin concentrations were lower in EFAD females (Table III). However, there were no significant differences in lean body mass or fat mass in proportion to body weight between the EFAD and control offspring of either gender. Furthermore, plasma triglyceride and cholesterol concentrations did not differ between the EFAD and control offspring (Table III).

Glucose metabolism. Fasting blood glucose and plasma insulin levels were higher in EFAD males compared to the controls, but did not differ in the females (Fig. 2A and D). No differences were found in blood glucose levels between EFAD and controls of either gender during the intraperitoneal glucose tolerance test (Fig. 2B and C). However, plasma insulin levels during the test were higher in the EFAD males compared to the controls $(\mathrm{p}<0.01)$, whereas no differences were noted between the females. Furthermore, in the females there was a clear first insulin peak in the two groups 2 min after glucose injection, but in the males this peak was less pronounced (Fig. 2E and F).

\section{Discussion}

The purpose of this study was to investigate the metabolic consequences of prenatal exposure to EFAD in mice. Our

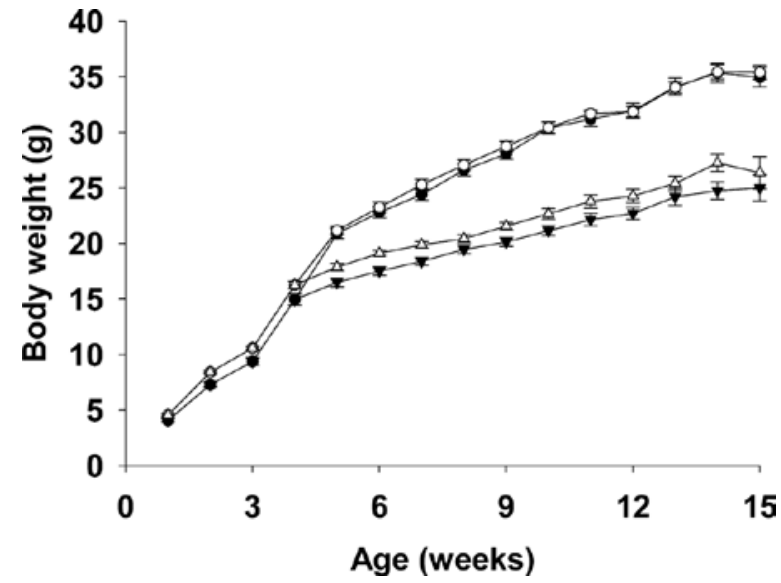

Figure 1. Body weight of EFAD and control mice. Male EFAD (black circles, $\mathrm{n}=15$ ), male control (white circles, $\mathrm{n}=11$ ), female EFAD (black triangles, $\mathrm{n}=15$ ) and female control (white triangles, $\mathrm{n}=11$ ); $\mathrm{p}<0.001$ between EFAD and the controls, weeks 1-4 (both genders); $\mathrm{p}<0.01$ between EFAD and control females, weeks 5-15, and not significant (ns) between EFAD and control males, weeks 5-15. Differences in body weight were analyzed by one-way repeated-measures ANOVA. Data are expressed as the mean \pm SEM.

results showed that an EFAD diet given to mouse dams during the latter half of gestation resulted in lower levels of essential fatty acids and their derivative PUFA in hepatic phospholipids of the newborn pups. Furthermore, prenatal EFAD resulted in higher fasting blood glucose and plasma insulin levels in the male offspring at 12 weeks of age, as well as higher plasma insulin levels during the intraperitoneal glucose tolerance test. The female offspring of the dams fed an EFAD diet had significantly lower body weight, lean body mass, leptin levels and a trend towards lower fat mass at 15 weeks of age compared to the controls.

The fatty acid composition of hepatic phospholipids confirmed EFAD in the newborn pups of dams fed solely on an EFAD diet during the last 10 days of gestation due to the low levels of n-3 and n-6 PUFA and high levels of mead acid (19). The timing of the EFAD diet in the present study 

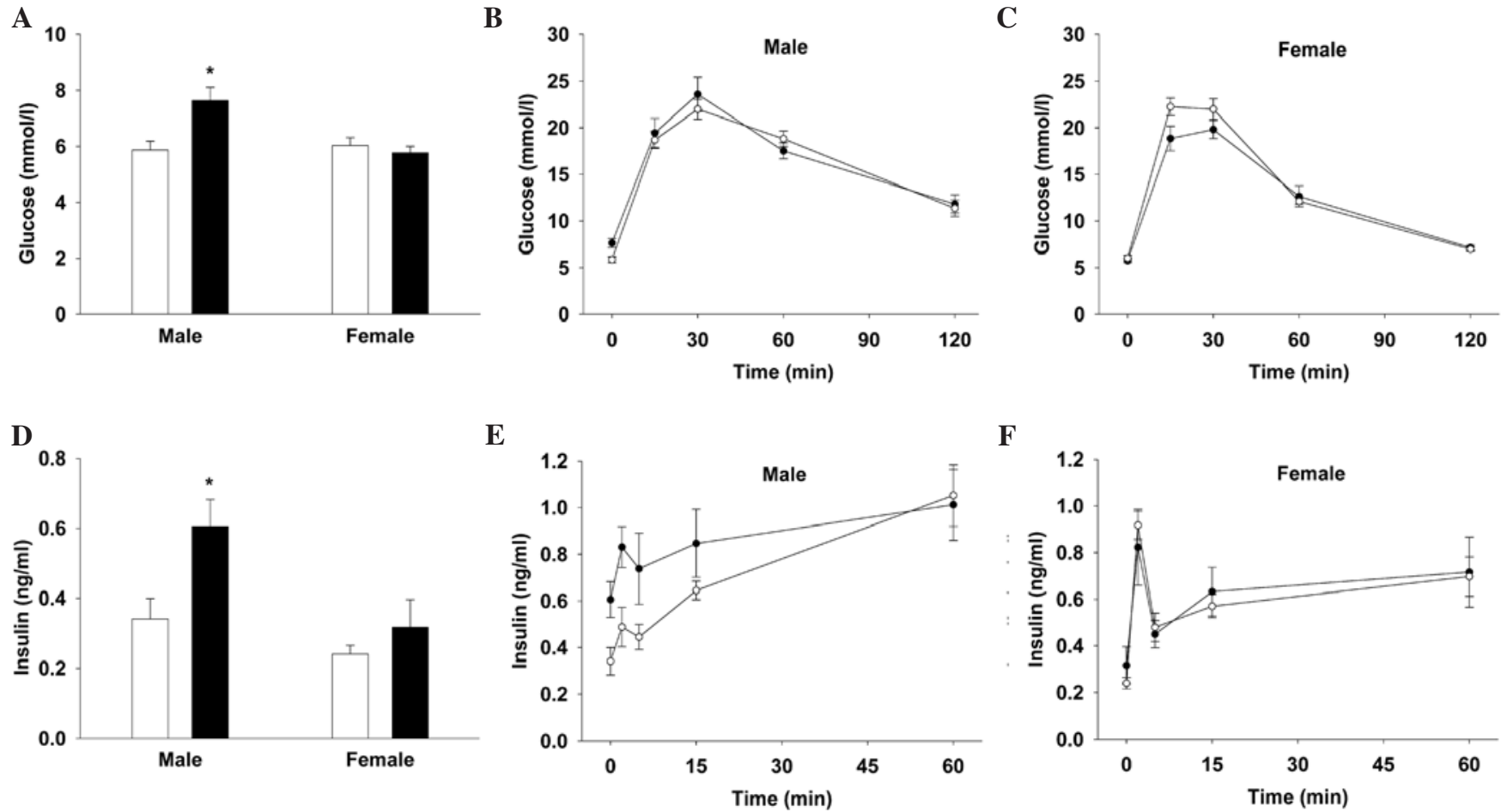

Figure 2. Glucose metabolism at 12 weeks of age. EFAD (black bars and circles) and control mice (white bars and circles). Blood glucose levels (A) in fasted mice, (B) in male (ns) and (C) female mice (ns) during an intraperitoneal glucose tolerance test (n=6). Plasma insulin levels (D) in fasted mice, (E) in male $(\mathrm{p}<0.01)$ and $(\mathrm{F})$ female mice $(\mathrm{ns})$ during an intraperitoneal glucose tolerance test $(\mathrm{n}=6)$. Differences in glucose and insulin levels during the glucose tolerance test were analyzed by one-way repeated measures ANOVA. Data are expressed as the mean \pm SEM; ${ }^{*}$ p $<0.05$ between EFAD and the controls.

resulted as expected in EFAD pups, without affecting litter size or survivarl rate (12). Results of the present study in pups with EFAD were as expected, but no differences were found in litter size or survival between EFAD and the control pups.

The body weight of the EFAD pups was lower than that of the controls during the first 4 weeks of life, which is consistent with earlier studies of rodents subjected to prenatal (20) or perinatal (12) EFAD. The lower body weight of the EFAD pups during the first weeks after birth indicates that the maternal EFAD diet had an inhibitory effect on the growth of the pups, which lasted throughout the lactation period. A similar delay in recovery of body weight after prenatal exposure to EFAD has been demonstrated in mouse pups that were cross-fostered at birth to control dams (20). The mechanisms behind the slower growth of EFAD animals have yet to be clarified. Decreased levels of prostaglandin $\mathrm{E}_{2}$, a metabolite of arachidonic acid, has been suggested as a mechanism due to its growth-promoting effects, its effects on growth-related gene expression and on calcium metabolism $(21,22)$. Early growth restriction by EFAD shows diverse effects on body weight during adult life depending on the study design. Male rat offspring exposed to EFAD during the latter half of pregnancy and throughout lactation had a rapid catch-up growth after weaning and increased body weight as adults (14). However, both male and female mouse offspring of dams exposed to EFAD mainly during lactation were lean, with low leptin levels as adults (23). The female, but not the male, offspring in this study had significantly lower body weight and leptin levels compared to the controls in adulthood. These findings show that prenatal EFAD exposure affects the adult body weight in a gender-specific manner.
Long-term effects on body weight in other models of nutritional restrictions during pregnancy have yielded mixed results. Calorie restriction (50\% of normal intake) of mice late in gestation did not affect body weight or food intake in offspring of either gender, but increased the relative body fat content in males at 6 months of age (24). No difference was found in the body weight of 15 -week-old rat offspring of either gender from dams fed a low-protein diet or a control diet during the entire gestation (25). Studies of humans exposed to prenatal undernutrition during the Dutch famine demonstrate that undernutrition early in pregnancy resulted in increased obesity rates in males at a young age (26) and increased BMI in females at 50 years of age (27). Conversely, undernutrition during the late prenatal period and the first months of life resulted in lower rates of obesity in 19-year-old males (26). Taken together, these studies indicate that malnutrition late in gestation is not associated with increased body weight, which is in line with the results of the present study where the EFAD diet had no effect on body weight in male mice and caused lower body weight in female mice.

Epidemiological studies of the Dutch famine have shown that prenatal exposure to undernutrition, especially during the last trimester, is linked to lower glucose tolerance during adult life (28). A study investigating the association between small birth size and glucose tolerance showed that males, but not females, who were shorter or lighter at birth were less insulin-sensitive and had a higher insulin secretion at 20 years of age (29). No differences were noted in the blood glucose levels during the glucose tolerance test in either gender of the mouse offspring in our study. Furthermore, no differ- 
ences in fasting blood glucose or plasma insulin levels were observed in the females. However, the male EFAD offspring had significantly higher plasma insulin levels during the glucose tolerance test compared to the controls, indicating decreased insulin sensitivity. Additionally, the male EFAD offspring had higher fasting blood glucose and plasma insulin levels compared to the controls. Similar to these data, other experimental studies show gender-specific effects on glucose homeostasis in adult offspring as a result of prenatal malnutrition. In rats fed a low-protein diet during the entire pregnancy, the adult male, but not the female, offspring had increased glucose and insulin levels $(25,30)$. Mice that were exposed to a $50 \%$ calorie restriction during the last prenatal week showed a progressive decline in glucose tolerance with age in the males (significant at 6 months of age), which was less pronounced in the females (31). Another study showed that male, but not female, C57BL/6 mice developed impaired glucose tolerance as early as 12 weeks of age when exposed to a $30 \%$ calorie restriction during prenatal life (32). These data suggest that male rodents are more sensitive to prenatal nutritional programming than females.

The underlying mechanisms for the decreased insulin sensitivity in the EFAD-exposed males remain to be determined. According to the fetal origin of adult disease hypothesis, malnutrition at critical periods of intrauterine development causes permanent changes in the structure and or function of the developing endocrine status of the fetus (33). This reprogramming consists mainly of the development of insulin resistance, which, in turn, enables sparing use of energy in times of nutritional deprivation, but may in the long term facilitate the development of glucose intolerance and diabetes (34). Regarding the sex differences of glucose metabolism in the present study, the gender hormones of estrogen and testosterone may be involved. The $17-\beta$ estrogen has previously been shown to play a protective role in the development of insulin resistance in ovariectomised rats fed normal chow (35). In contrast, testosterone has been shown to increase insulin resistance in sheep and rats. Female sheep treated prenatally with testosterone showed similar insulin sensitivity later in life to that noted in untreated males (36), and female rats treated prenatally with testosterone exhibited hyperinsulinemia in adult life (37). Thus, sex hormone levels may mediate differences in the development of pancreatic differentiation or function. Since male mice are intrinsically more vulnerable to disturbed insulin sensitivity, they are probably more disposed to developing insulin sensitivity when exposed to fetal malnutrition.

In conclusion, exposure to an EFAD diet during the last 10 days of gestation results in long-term gender-specific effects on body composition and glucose metabolism in the offspring, suggesting that the fatty acid composition of the maternal diet during fetal life affects the metabolism in adulthood.

\section{Acknowledgements}

The Centre for Physiology and Bio-Imaging at Sahlgrenska Academy at Gothenburg University, and the technical assistance of Jing Jia and Berit Holmberg are gratefully acknowledged. This study was supported by the Swedish Research Council (K2009-65X-15424-05-3), the Faculty of Medicine at the University of Gothenburg, the National Board of Health and Welfare, the Magnus Bergvall Foundation, the Fredrik and Ingrid Thuring Foundation, the Åke Wiberg Foundation, the Gothenburg Children's Hospital Research Fund, the Sahlgrenska University Hospital Funds and the Royal Society of Sciences and Letters in Gothenburg.

\section{References}

1. Simmons R: Perinatal programming of obesity. Exp Gerontol 40: 863-866, 2005.

2. Smit EN, Muskiet FA and Boersma ER: The possible role of essential fatty acids in the pathophysiology of malnutrition: a review. Prostaglandins Leukot Essent Fatty Acids 71: 241-250, 2004.

3. Holman RT, Johnson SB, Mercuri O, Itarte HJ, Rodrigo MA and De Tomas ME: Essential fatty acid deficiency in malnourished children. Am J Clin Nutr 34: 1534-1539, 1981.

4. Koletzko B, Abiodun PO, Laryea MD and Bremer HJ: Fatty acid composition of plasma lipids in Nigerian children with proteinenergy malnutrition. Eur J Pediatr 145: 109-115, 1986.

5. Wolff JA, Margolis S, Bujdoso-Wolff K, Matusick E and MacLean WC Jr: Plasma and red blood cell fatty acid composition in children with protein-calorie malnutrition. Pediatr Res 18: 162-167, 1984.

6. Foreman-van Drongelen MM, al MD, van Houwelingen AC, Blanco CE and Hornstra G: Comparison between the essential fatty acid status of preterm and full-term infants, measured in umbilical vessel walls. Early Hum Dev 42: 241-251, 1995.

7. Hjelte L, Ahren B, Andren-Sandberg A, Bottcher G and Strandvik B: Pancreatic function in the essential fatty acid deficient rat. Metabolism 39: 871-875, 1990.

8. Lefkowith J, Schreiner G, Cormier J, et al: Prevention of diabetes in the BB rat by essential fatty acid deficiency. Relationship between physiological and biochemical changes. J Exp Med 171: 729-743, 1990.

9. Robertson RP and Chen M: A role for prostaglandin $\mathrm{E}$ in defective insulin secretion and carbohydrate intolerance in diabetes mellitus. J Clin Invest 60: 747-753, 1977.

10. Weisinger HS, Armitage JA, Sinclair AJ, Vingrys AJ, Burns PL and Weisinger RS: Perinatal omega-3 fatty acid deficiency affects blood pressure later in life. Nat Med 7: 258-259, 2001.

11. Mathai ML, Soueid M, Chen N, et al: Does perinatal omega-3 polyunsaturated fatty acid deficiency increase appetite signaling? Obes Res 12: 1886-1894, 2004.

12. Korotkova M, Gabrielsson B, Hanson LA and Strandvik B: Maternal essential fatty acid deficiency depresses serum leptin levels in suckling rat pups. J Lipid Res 42: 359-365, 2001.

13. Korotkova M, Gabrielsson B, Hanson LA and Strandvik B: Maternal dietary intake of essential fatty acids affects adipose tissue growth and leptin mRNA expression in suckling rat pups. Pediatr Res 52: 78-84, 2002.

14. Korotkova M, Ohlsson C, Gabrielsson B, Hanson LA and Strandvik B: Perinatal essential fatty acid deficiency influences body weight and bone parameters in adult male rats. Biochim Biophys Acta 1686: 248-254, 2005.

15. Rose HG and Oklander M: Improved procedure for the extraction of lipids from human erythrocytes. J Lipid Res 6: 428-431, 1965.

16. Steel DM, Ryd W, Ascher H and Strandvik B: Abnormal fatty acid pattern in intestinal mucosa of children with celiac disease is not reflected in serum phospholipids. J Pediatr Gastroenterol Nutr 43: 318-323, 2006.

17. Venken K, Moverare-Skrtic S, Kopchick JJ, et al: Impact of androgens, growth hormone, and IGF-I on bone and muscle in male mice during puberty. J Bone Miner Res 22: 72-82, 2007.

18. Moverare-Skrtic S, Venken K, Andersson N, et al: Dihydrotestosterone treatment results in obesity and altered lipid metabolism in orchidectomized mice. Obesity (Silver Spring) 14: 662-672, 2006.

19. Fulco AJ and Mead JF: Metabolism of essential fatty acids. VIII. Origin of 5,8,11-eicosatrienoic acid in the fat-deficient rat. J Biol Chem 234: 1411-1416, 1959.

20. Berkow SE and Campagnoni AT: Essential fatty acid deficiency: effects of cross-fostering mice at birth on brain growth and myelination. J Nutr 111: 886-894, 1981.

21. Kruger MC and Horrobin DF: Calcium metabolism, osteoporosis and essential fatty acids: a review. Prog Lipid Res 36: 131-151, 1997. 
22. Sellmayer A, Danesch U and Weber PC: Effects of different polyunsaturated fatty acids on growth-related early gene expression and cell growth. Lipids 31 (Suppl): S37-S40, 1996.

23. Palsdottir V, Wickman A, Andersson N, Hezaveh R, Olsson B, Gabrielsson BG and Strandvik B: Postnatal deficiency of essential fatty acids in mice results in resistance to diet-induced obesity and low plasma insulin during adulthood. Prostaglandins Leukot Essent Fatty Acids 84: 85-92, 2011.

24. Jimenez-Chillaron JC, Hernandez-Valencia M, Lightner A, et al: Reductions in caloric intake and early postnatal growth prevent glucose intolerance and obesity associated with low birthweight. Diabetologia 49: 1974-1984, 2006.

25. Zambrano E, Bautista CJ, Deas M, et al: A low maternal protein diet during pregnancy and lactation has sex- and window of exposure-specific effects on offspring growth and food intake, glucose metabolism and serum leptin in the rat. J Physiol 571: 221-230, 2006.

26. Ravelli GP, Stein ZA and Susser MW: Obesity in young men after famine exposure in utero and early infancy. N Engl J Med 295: 349-353, 1976.

27. Ravelli AC, van Der Meulen JH, Osmond C, Barker DJ and Bleker OP: Obesity at the age of $50 \mathrm{y}$ in men and women exposed to famine prenatally. Am J Clin Nutr 70: 811-816, 1999.

28. Ravelli AC, van der Meulen JH, Michels RP, Osmond C, Barker DJ, Hales CN and Bleker OP: Glucose tolerance in adults after prenatal exposure to famine. Lancet 351: 173-177, 1998.

29. Flanagan DE, Moore VM, Godsland IF, Cockington RA, Robinson JS and Phillips DI: Fetal growth and the physiological control of glucose tolerance in adults: a minimal model analysis. Am J Physiol Endocrinol Metab 278: E700-E706, 2000.
30. Zambrano E, Martinez-Samayoa PM, Bautista CJ, et al: Sex differences in transgenerational alterations of growth and metabolism in progeny (F2) of female offspring (F1) of rats fed a low protein diet during pregnancy and lactation. J Physiol 566: 225-236, 2005 .

31. Jimenez-Chillaron JC, Hernandez-Valencia M, Reamer C, et al: Beta-cell secretory dysfunction in the pathogenesis of low birth weight-associated diabetes: a murine model. Diabetes 54: 702-711, 2005.

32. Knight BS, Pennell CE, Adamson SL and Lye SJ: The impact of murine strain and sex on postnatal development after maternal dietary restriction during pregnancy. J Physiol 581: 873-881, 2007.

33. Robinson R: The fetal origins of adult disease. BMJ 322: 375-376, 2001.

34. Reusens B and Remacle C: Programming of the endocrine pancreas by the early nutritional environment. Int $\mathrm{J}$ Biochem Cell Biol 38: 913-922, 2006.

35. Kumagai S, Holmang A and Bjorntorp P: The effects of oestrogen and progesterone on insulin sensitivity in female rats. Acta Physiol Scand 149: 91-97, 1993.

36. Recabarren SE, Padmanabhan V, Codner E, et al: Postnatal developmental consequences of altered insulin sensitivity in female sheep treated prenatally with testosterone. Am J Physiol Endocrinol Metab 289: E801-E806, 2005.

37. Demissie M, Lazic M, Foecking EM, Aird F, Dunaif A and Levine JE: Transient prenatal androgen exposure produces metabolic syndrome in adult female rats. Am J Physiol Endocrinol Metab 295: E262-E268, 2008. 
